Important Gaps in HIV Knowledge, Attitudes and Practices Among Young Asylum Seekers in Comparison to the General Population

\title{
Tiittala, Paula
}

2018-12

Tiittala , P , Kivelä , P , Liitsola , K, Ollgren , J , Pasanen , S , Vasankari , T \& Ristola , M 2018 , ' Important Gaps in HIV Knowledge, Attitudes and Practices Among Young Asylum Seekers in Comparison to the General Population ' , Journal of Immigrant and Minority Health , vol. 20 , no. 6 , pp. 1415-1423 . https://doi.org/10.1007/s10903-018-0707-8

http://hdl.handle.net/10138/278323

https://doi.org/10.1007/s10903-018-0707-8

publishedVersion

Downloaded from Helda, University of Helsinki institutional repository.

This is an electronic reprint of the original article.

This reprint may differ from the original in pagination and typographic detail.

Please cite the original version. 


\title{
Important Gaps in HIV Knowledge, Attitudes and Practices Among Young Asylum Seekers in Comparison to the General Population
}

\author{
Paula Tiittala $^{1,3}$ (1) Pia Kivelä ${ }^{2} \cdot$ Kirsi Liitsola $^{3} \cdot$ Jukka Ollgren $^{3} \cdot$ Sini Pasanen $^{4} \cdot$ Tuula Vasankari $^{5} \cdot$ Matti Ristola $^{2}$
}

Published online: 8 February 2018

(c) Springer Science+Business Media, LLC, part of Springer Nature 2018

\begin{abstract}
Migrants are disproportionately affected by HIV in many European countries, including Finland. We aimed to compare the HIV-related knowledge, attitudes and practices (KAP) of young asylum seekers to those of the general young adult population. Two cross-sectional surveys were conducted among 20- to 25-year-old young adults: The TIE study among asylum seekers $(n=47)$ and the World AIDS Day 2014 study among the general population $(n=485)$. Important gaps in HIV KAP were identified especially among the young asylum seekers. For the general young adult population, previous HIV testing was associated with female gender, better HIV knowledge and increased sexual activity. Health education concerning HIV needs to be further enforced among young adults in Finland. Due to poorer HIV knowledge, young asylum seekers might be especially vulnerable to HIV. The asylum process is a window of opportunity for health education and HIV testing.
\end{abstract}

Keywords HIV $\cdot$ KAP $\cdot$ Testing $\cdot$ Asylum seeker $\cdot$ Young adult

\section{Introduction}

Migrants are disproportionately affected by HIV/AIDS in many European countries and are recognized as a key population at high risk of HIV [1-3]. In Finland, $60 \%$ of the new infections in 2016 were diagnosed among individuals of foreign origin [4]. The risk of HIV among migrants is influenced by individual and pre-, inter- and post-migration factors $[5,6]$. Stigma, and misconceptions related to HIV and health care services result in higher barriers to HIV testing and counseling among migrants [7]. Member states of WHO Europe, including Finland, have committed themselves to ensuring capacities for appropriately addressing

Paula Tiittala

paula.tiittala@thl.fi

1 Doctoral Programme in Population Health, University of Helsinki, Helsinki, Finland

2 Department of Infectious Diseases, Helsinki University Hospital, Helsinki, Finland

3 Department of Health Security, National Institute for Health and Welfare, Mannerheimintie 166, 00271 Helsinki, Finland

4 Positiiviset ry, HivFinland, on behalf of the World Aids Day committee 2014, Helsinki, Finland

5 Finnish Lung Health Association (Filha), on behalf of the TIE steering committee, Helsinki, Finland communicable diseases, including HIV/AIDS, among different migrant populations [8].

Asylum seekers are forced migrants who have sought international protection and whose claim for refugee status has not yet been determined [8]. In 2015, the number of asylum applications in Finland grew nine-fold, its relative increase being the highest in Europe. The majority of the applicants were young men from Iraq, Afghanistan and Somalia [9]. Reports on the prevalence of HIV among forced migrants in Europe suggest that this population is especially vulnerable to HIV [10-13].

Adolescents and young adults represent the next generation on which to focus in the prevention of HIV and other sexually transmitted diseases [14]. Young people accounted for $11 \%$ of the new HIV diagnoses in Europe in 2015; the highest rate of new diagnoses being in the age group of 25-29 years [15]. Infections among migrants in Europe seem to occur at a younger age than that of the general population [3]. Several European countries have adopted screening policies for HIV among asylum seekers [16]. In 2014, 6.5\% of the young adults aged 20-25 years in Finland had foreign origin and were born abroad [17].

Committing itself to the battle against HIV among young adults, in 2001 the United Nations General Assembly Special Session (UNGASS) on HIV/AIDS agreed to develop common indicators to monitor the HIV/AIDS epidemic; one 
of these being the assessment of young people's HIV-related knowledge $[14,18]$.

Several studies have evaluated HIV-related KAP among migrants in Europe [13, 19-25]. However, only a few have attempted to compare the KAP of migrants to that of the general population $[13,24]$. Therefore, we aimed to study the possible differences between the HIV KAP of young asylum seekers and that of the general population in Finland, and to reveal possible needs for health education.

\section{Methods}

TIE was a cross-sectional study by convenience sample, which assessed the HIV- and tuberculosis-related KAP of young asylum seekers in Finland. The inclusion criteria for the study were (1) asylum seeker status; (2) living in one of three selected reception centers in Helsinki or Turku; (3) age of 16-25 years; and (4) being originally from North Africa or the Eastern Mediterranean region, the Former Soviet Union countries or Sub-Saharan Africa. Knowledge regarding HIV and tuberculosis was assessed using a structural self-administered 50-item anonymous questionnaire, translated into Arabic, Soran, Russian and English. The questionnaire was filled out in a classroom setting, with assistance available for those with reading difficulties. After completion, the participants had the opportunity to ask the reception center nurse and study physician questions. The interviews took place between January 1st and May 31st, 2014. Participation in the study was voluntary and answering all questions was not required. The study was approved by the coordinating medical ethical committee of the Hospital District of Helsinki and Uusimaa (289/13/03/00/13).

The World AIDS Day Study 2014 (WAD 2014) was a population-based cross-sectional survey in Finnish with an electronic 17-item questionnaire on HIV KAP. The eligibility criteria for the WAD 2014 study were (1) age of 20 to 29 years; (2) Finnish residency; and (3) having electronic contact information in the Taloustutkimus ltd's register. Taloustutkimus ltd is a commercial market research center that conducts consumer surveys for its clients. The company adheres to the standards of International Chamber of Commerce (ICC) and European Society for Opinion and Marketing Research (ESOMAR) aiming to improve the quality and reliability of the internet based surveys. Company's internet panel was established in 1997. Members of the panel have been recruited from previous studies that have sampled individuals from the population register. A total of 5931 individuals were randomly selected from the panel and recruited via an email invitation letter, which contained a personal user identification code and a password to a Computer Aided Web Interview portal. The questionnaire was open from 20th to 30th October 2014. No reminders were sent. Answering all questions was required in order to complete the survey.

The TIE and WAD 2014 studies were conducted independently of each other. Same age groups (20-25 years of age) were analyzed in both samples.

\section{Socio-demographic Variables}

The WAD 2014 study retrieved information on socio-demographic background from the Taloustutkimus register. In the TIE study, this information was self-reported. In the TIE study, the country of origin was recoded into region of origin. The Eastern Mediterranean region included Egypt, Iran, Iraq, Morocco, Saudi Arabia, Somalia and Syria as countries of origin. The Sub-Saharan African region included individuals from Algeria, Cameroon, Eritrea, Ethiopia, Gambia and Nigeria. A common region of origin was also coded for individuals from Russia or countries of the Former Soviet Union.

\section{Assessment of HIV Knowledge, Attitudes and Practices}

Both surveys included questions on HIV transmission and prevention, attitudes towards people living with HIV (PLWH), and practices related to HIV. In both studies, HIV knowledge was assessed using questions from the validated and internationally recognized UNGASS indicator (Table 1) [14, 18]: The TIE study included questions 1-5 and the WAD 2014 study questions $2-5$. Knowledge was evaluated in the light of both individual indicator questions and a composite score that represented the proportion of individuals who gave the correct answer to all four UNGASS indicator questions (question 2-5). Missing responses were interpreted as false.

In the TIE study, additional questions assessing HIV KAP were developed on the basis of previous publications and in consultation with a cultural anthropologist. In the WAD 2014 study, previous HIV testing on the individual's own initiative was surveyed in order to exclude universal provider-initiated testing performed, for example, during antenatal screening. The WAD study also included questions on sexual behavior. Participants in both studies were asked to name what they thought were the best strategies to disseminate HIV-related information to young people such as themselves.

\section{Statistical Analyses}

IBM SPSS Statistics 23 was used for the statistical analyses. For the WAD 2014 study, Taloustutkimus Ltd developed sample weights using gender, age group (20-24 and 25-29) and region of origin as auxiliary variables to improve the 
Table 1 United Nations General Assembly Special Session on HIV/ AIDS (UNGASS) core indicators of young peoples' knowledge about HIV prevention. (Adapted from United Nations General Assembly
Special Session on HIV/AIDS Monitoring the Declaration of Commitment on HIV/AIDS, Guidelines on Construction of Core Indicators, 2010 Reporting [18])

\begin{tabular}{llc}
\hline Number & Indicator question $^{\mathrm{a}}$ & Correct answer $^{\mathrm{a}}$ \\
\hline 1 & $\begin{array}{l}\text { Can the risk of HIV transmission be reduced by having sex with only one uninfected partner who has } \\
\text { no other partners? }\end{array}$ & Yes \\
2 & Can a person reduce the risk of getting HIV by using a condom every time they have sex? & Yes \\
3 & Can a healthy-looking person have HIV? & Nes \\
5 & Can a person get HIV from mosquito bites? & No \\
\hline
\end{tabular}

${ }^{\text {a}}$ Response options to all questions were Yes/No/I don’t know

representativeness of the sample with respect to the general population in Finland. The TIE study used the Pearson chisquared test to compare categorical variables by univariable analysis, and calculated $95 \%$ confidence intervals (CI) by bootstrapping. The WAD 2014 study used complex samples logistic regression to compare categorical variables with the Wald F-test and to estimate odds ratios (OR) and their 95\% CIs. Complex samples multivariable logistic regression was used to assess independent predictors of the exposure to previous HIV testing. Variables with univariable $\mathrm{p}<0.20$ were chosen for the multivariable analysis. $p$ values were two tailed and values $<0.05$ were considered statistically significant. Results from TIE and WAD 2014 studies were compared using the $95 \%$ CIs. If the CIs did not overlap, the result was considered statistically significant.

\section{Results}

\section{Socio-demographic Variables}

Altogether 68 asylum seekers participated in TIE study. Only those 47 individuals aged 20 to 25 years were included in the analyses (Table 2). The participants' mean age was 22.3 years (95\% CI 21.8-22.9). Women more often reported being in a steady relationship than men (60.0 vs. $20.0 \%$ respectively, $\mathrm{p}<0.05)$. Women had registered their asylum application significantly earlier than men $(\mathrm{p}<0.05)$. Participants from North Africa and Eastern Mediterranean region had less secondary or tertiary education than participants from other regions $(\mathrm{p}<0.05)$.

WAD study enrolled 1011 individuals of whom 485 persons aged 20-25 years were included in the analyses (Table 2). After weighting adjustment, the mean age of the general young adult population was 22.8 years (95\% CI 22.6-22.9\%). Women were significantly more often in a steady relationship than men $(45.2$ vs. $27.2 \%, \mathrm{p}<0.01)$. We observed no other significant differences in socio-demographic background by gender or region of origin.
There were significantly more men among the TIE participants in comparison to the general young adult population in WAD 2014 study as evaluated by overlapping of the $95 \%$ CIs (Table 2). Young asylum seekers were also significantly less educated than general young adult population. Smaller proportion of asylum seekers did not know somebody with HIV as compared to the general population but no difference was observed among those who knew somebody with HIV.

\section{HIV Knowledge}

Young asylum seekers had more misconceptions regarding HIV than the general young adult population (Graph 1). Of the young asylum seekers, 6.4\% (95\% CI 0-14.3\%) had an all-correct UNGASS composite score, whereas the rate of composite score was 50.3\% (95\% CI 45.5-55.0\%) among the general young adult population. Knowledge gaps between the populations were especially pronounced regarding whether a healthy-looking person can have HIV (UNGASS 3), whether HIV can be transmitted by sharing a meal (UNGASS 5), and whether HIV can be treated. Predominantly the differences persisted after stratification by gender and level of education. However, there was no significant difference between better educated asylum seeker and general young adult population men with respect to knowledge on condom use (UNGASS 2) and that HIV cannot transmit through kissing. Among the young asylum seekers, knowledge level was consistently low across all indicator questions. The general young adult population was least knowledgeable that HIV is not transmitted through mosquito bites (UNGASS 4).

Among the asylum seekers, originating from Sub-Saharan Africa was associated with a higher UNGASS composite score $(p<0.01)$ than originating from North Africa and Eastern Mediterranean or former Soviet Union regions. Asylum seekers that had arrived in 2014 had a lower UNGASS composite score ( 0 vs. $15.8 \%$ respectively, $\mathrm{p}<0.05)$ and poorer knowledge regarding whether HIV was transmitted through mosquito bites ( 8.7 vs. $50.0 \%, \mathrm{p}<0.01)$ than those who had arrived before 2014. Neither marital status, reading ability, 
Table 2 Basic characteristics of study populations

\begin{tabular}{|c|c|c|c|c|}
\hline \multirow[t]{2}{*}{ Characteristic } & \multicolumn{2}{|c|}{ TIE study $2014(\mathrm{n}=47)$} & \multicolumn{2}{|c|}{ World Aids Day Study $2014(\mathrm{n}=485)$} \\
\hline & $\%(\mathrm{n})$ & $95 \% \mathrm{CI}$ & Unweighted [\% (n)] & Weighted \% (95\% CI) \\
\hline \multicolumn{5}{|l|}{ Age (years) } \\
\hline 20 & $23.4(11)$ & $11.6-35.2$ & $10.7(52)$ & $13.2(10.1-17.0)$ \\
\hline 21 & $17.0(8)$ & $6.5-28.6$ & $11.3(55)$ & $14.0(10.8-17.9)$ \\
\hline 22 & $10.6(5)$ & $2.4-21.3$ & $13.8(67)$ & $15.9(12.6-19.9)$ \\
\hline 23 & $12.8(6)$ & $4.3-23.4$ & $13.0(63)$ & $14.4(11.3-18.1)$ \\
\hline 24 & $23.4(24)$ & $11.9-37.2$ & $21.6(105)$ & $25.1(21.1-29.6)$ \\
\hline 25 & $12.8(6)$ & $4.3-22.4$ & $29.5(143)$ & $17.4(14.7-20.5)$ \\
\hline \multicolumn{5}{|l|}{ Gender } \\
\hline Men & $78.3(36)$ & $65.3-89.5$ & $37.9(184)$ & $50.8(46.1-55.6)$ \\
\hline Women & $21.7(10)$ & $10.5-34.7$ & $62.1(301)$ & $49.2(44.4-53.9)$ \\
\hline Missing & 1 & & & \\
\hline \multicolumn{5}{|l|}{ Education $^{a}$} \\
\hline Primary education or less & $62.2(28)$ & 47.7-75.6 & $12.0(58)$ & 13.4 (10.4-17.1) \\
\hline Secondary & $15.6(7)$ & $6.3-27.3$ & $67.6(328)$ & $69.7(65.2-73.9)$ \\
\hline Tertiary & $22.2(10)$ & $10.2-34.6$ & 20.4 (99) & $16.9(13.8-20.5)$ \\
\hline Missing & 2 & & & \\
\hline \multicolumn{5}{|l|}{ Maritial status } \\
\hline Single & $71.7(33)$ & $57.8-84.1$ & $57.7(280)$ & $63.9(59.2-68.4)$ \\
\hline Married or co-habitated & $28.3(13)$ & $15.9-42.2$ & $38.4(186)$ & $36.1(31.6-40.8)$ \\
\hline Missing & 1 & & 19 & \\
\hline \multicolumn{5}{|c|}{ Do you know somebody who has HIV infection? } \\
\hline Yes & $9.5(4)$ & $2.2-18.6$ & $1.4(7)$ & $1.7(0.8-3.7)$ \\
\hline No & $90.5(38)$ & 81.4-97.8 & $70.1(340)$ & $71.2(66.7-75.3)$ \\
\hline I don't know & NA & NA & $28.5(138)$ & $27.1(23.1-31.6)$ \\
\hline Missing & 5 & & & \\
\hline \multicolumn{5}{|l|}{ Area of residency } \\
\hline Helsinki area & NA & NA & $28.9(140)$ & $30.0(25.8-34.5)$ \\
\hline Other Southern Finland & & & $18.8(91)$ & $19.6(16.1-23.7)$ \\
\hline Western Finland & & & $28.0(136)$ & $26.0(22.0-30.4)$ \\
\hline Eastern and Northern Finland & & & $24.3(118)$ & $24.4(20.5-28.8)$ \\
\hline \multicolumn{5}{|l|}{ Region of origin } \\
\hline North Africa and Middle East & $78.3(36)$ & $65.9-89.7$ & NA & NA \\
\hline Sub-Saharan Africa & $15.2(7)$ & $5.6-27.3$ & & \\
\hline Russia or former Soviet & $6.5(3)$ & $0-14.3$ & & \\
\hline Union & 1 & & & \\
\hline Missing & & & & \\
\hline \multicolumn{5}{|l|}{ Time of arrival to Finland } \\
\hline In 2014 & $59.6(28)$ & $44.7-73.3$ & NA & NA \\
\hline Before 2014 & $40.4(19)$ & $26.7-55.3$ & & \\
\hline \multicolumn{5}{|c|}{ How well do you read in your mother tongue? } \\
\hline Poorly or not at all & $17.0(8)$ & $7.0-28.6$ & NA & NA \\
\hline Well or fairly well & $83.0(39)$ & $71.4-93.0$ & & \\
\hline \multicolumn{5}{|l|}{$\begin{array}{l}\text { How well do you write in your } \\
\text { mother tongue? }\end{array}$} \\
\hline Poorly or not at all & $23.4(11)$ & $12.5-35.6$ & NA & NA \\
\hline Well or fairly well & $76.6(36)$ & $64.4-87.5$ & & \\
\hline \multicolumn{5}{|c|}{ How do you consider your health at the moment? } \\
\hline $\mathrm{Bad}$ & $15.2(7)$ & $4.9-26.3$ & NA & NA \\
\hline Fair & $19.6(9)$ & $8.5-32.6$ & & \\
\hline Good & $65.2(30)$ & $50.0-79.6$ & & \\
\hline
\end{tabular}


Table 2 (continued)

\begin{tabular}{llllll}
\hline Characteristic & \multicolumn{2}{l}{ TIE study $2014(\mathrm{n}=47)$} & & World Aids Day Study 2014 (n=485) \\
\cline { 2 - 2 } & $\%(\mathrm{n})$ & $95 \% \mathrm{CI}$ & & Unweighted [\% (n)] & Weighted \% (95\% CI) \\
\hline Missing & 1 & & & \\
How often do you use internet? & & & & NA \\
Not at all or sometimes & $64.1(41)$ & $51.6-76.6$ & & NA & \\
Often or daily & $35.9(23)$ & $23.4-48.4$ & & \\
Missing & 3 & & & \\
\hline
\end{tabular}

Bold values represent statistically significant differences between the study populations

Variable categories where 95\% confidence intervals between TIE and World Aids Day Study do not overlap are bolded. No missing values unless otherwise specified

NA not applicable

aPrimary education accounts for less than 10 years of schooling; secondary education accounts for up to 11 or 12 years of schooling; and tertiary education accounts for more than 13 years of schooling

Graph 1 Comparison of HIV knowledge, attitudes and practices among young asylum seekers (TIE study) and general young adult population (WAD 2014 study). Mean \%; 95\% Confidence Interval. Triangle young asylum seekers in the TIE study, Square young general population in the WAD 2014 study

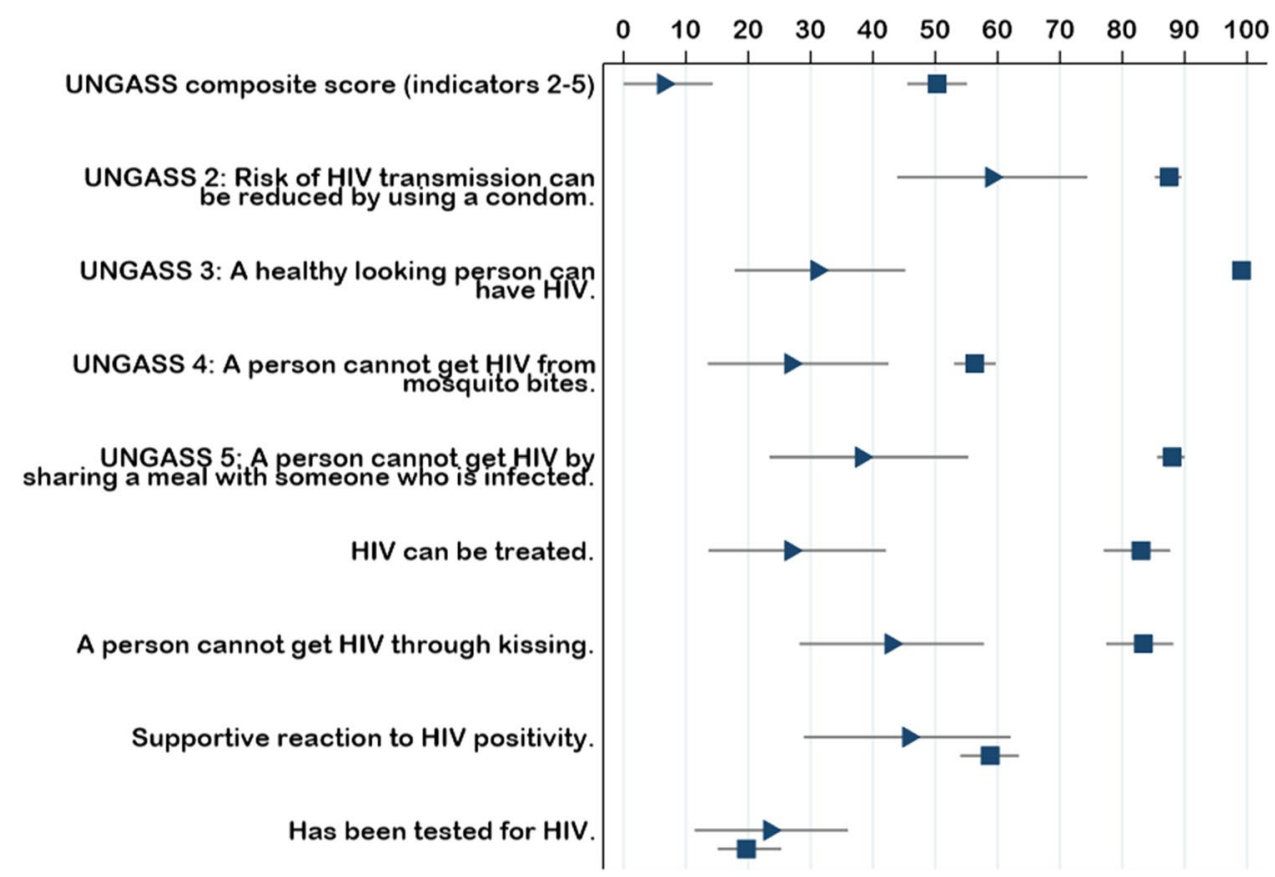

nor internet usage were associated with HIV knowledge among the young asylum seekers. Area of residency was not associated with HIV knowledge as assessed by either the UNGASS composite score or the individual indicator questions among the general young adult population.

Gender differences in HIV knowledge were observed among both study populations. Young asylum-seeking women had significantly better knowledge than men regarding whether HIV can be transmitted by sharing a meal ( 75.0 vs. $30.3 \%$ respectively, $p<0.05$ ). The UNGASS composite score among young asylum-seeking women seemed higher, although not significant, than that among men $(p=0.05)$. Among the general young adult population, women and those married knew significantly better than men and single individuals that a healthy-looking person can have HIV (UNGASS 3) (both p <0.01). In contrast, general young adult population men knew better than women that HIV cannot be transmitted from mosquito bites $(\mathrm{p}<0.01)$.

Having secondary education or higher was positively associated with knowledge regarding the benefits of condom use among the young asylum seekers $(p<0.01)$. In contrast, secondary education or higher was inversely associated with increased knowledge regarding HIV treatment possibilities (OR 0.385 , 95\% CI 0.155-0.955) among the general young adult population. Asylum seekers with poor reading ability were less aware that the risk of HIV cannot be reduced by having sex with only one faithful uninfected partner (UNGASS 1) than those who stated they could read well $(\mathrm{p}<0.05)$. 


\section{Attitudes to HIV}

Attitudes to PLWH were similarly supportive among both the young asylum seekers and the general young adult population across gender and educational levels (Graph 1). The belief that "HIV is a destiny" was supported by $17.6 \%$ (95\% CI 6.1-29.4\%) of the young asylum seekers and $45.0 \%$ (95\% CI 30.2-61.5\%) thought that "HIV is the result of promiscuity", with no significant gender differences. Only one asylum seeker stated that they would fear somebody they knew would be deported if diagnosed with HIV. Among the general young adult population, 79.0\% (95\% CI 74.8-82.6\%) thought that HIV testing should routinely be offered during health check-ups.

\section{Practices Related to HIV}

Similar proportions of individuals in both studies had previously been tested for HIV and the findings persisted after stratification by gender and level of education. Of the young asylum seekers, 23.4\% (95\% CI 11.4-35.7\%) reported previous HIV testing, with no significant differences according to gender or region of origin. Among the general young adult population, $18.0 \%$ (95\% CI 14.9-21.7\%) stated having be en HIV tested on their own initiative, and previous HIV testing was significantly more common among women than men ( 27.9 vs. $8.5 \%$ respectively, $\mathrm{p}<0.01$ ). Residents of Southern Finland had 1.81 (95\% CI 1.03-3.18) times higher odds of reporting previous history of HIV testing than the residents of Northern or Eastern Finland. Among the general young adult population, the most common explanation for no previous history of HIV testing was the belief that they could not have HIV $(91.0 \%, 95 \%$ CI 88.7-92.8\%) and that the idea had not occurred to them $(25.1 \%, 95 \%$ CI $21.9-28.6 \%)$.

Unprotected sex within the last six months was reported more often by single women $(27.8 \%, 95 \%$ CI $19.9-37.4 \%)$ than by single men $(14.4 \%, 95 \%$ CI $8.6-23.3 \%)$ in the general population $(\mathrm{p}<0.01)$. Unprotected sex with two or more partners within the last year was reported by $14.4 \%$ (95\% CI 10.7-19.1\%) of the young women and $8.3 \%$ (95\% CI $5.0-13.2 \%$ ) of the young men in the general population $(p=0.05)$. Unprotected sex was not associated with HIV KAP.

In the multivariable model, previous HIV testing among the general young adult population was associated with gender, knowledge that a healthy-looking person can have HIV (UNGASS 3) and having had unprotected sex with two or more partners during the last year (Table 3).

\section{Sources of Hiv-Related Information}

The young asylum seekers stated television $(59.6 \%, 95 \% \mathrm{CI}$ $46.2-74.5 \%)$, the internet $(53.2 \%, 95 \%$ CI $38.8-67.4 \%)$ and health workers $(46.8 \%, 95 \%$ CI $33.3-60.9 \%)$ as the three most popular sources of information on HIV, with no significant gender differences. Among the general young adult population, the most popular sources of information were school nurse $(75.4 \%, 95 \%$ CI $71.0-79.3 \%)$, parents (51.6\%, 95\% CI 46.8-56.3\%) and events organized at schools (47.5\%, 95\% CI 42.7-52.2\%). General young adult population women reported significantly more information-sharing by parents and school events than men $(\mathrm{p}<0.05$ and $<0.01$ respectively). Among general young adult population men, teachers were the third most popular source of information on sexual health and HIV $(48.1 \%, 95 \%$ CI $40.6-55.6 \%)$.

\section{Discussion}

To our knowledge, this was the first study to compare HIV KAP between young asylum seekers and the same-aged general young adult population. The results indicate major differences between the populations, especially regarding HIV knowledge.

HIV knowledge, as assessed by the UNGASS composite score, fell behind the international target level of 95\% by 2010 , among both populations [14]. The difference was especially pronounced if we take into account that only four out of five indicator questions were included in the composite score. Overall, the general young adult population had more knowledge regarding HIV than the young asylum seekers. As the risk of HIV is also elevated post-migration [26], these gaps in HIV KAP should be addressed appropriately.

The major gap in knowledge between the study populations related to whether a healthy-looking person can have HIV. This misconception can result in unrecognized risk behavior [14]. Indeed, among the general young adult population, better knowledge was an independent predictor of previous HIV testing.

Another important knowledge gap between the populations was observed regarding the statement whether HIV can be treated. Asylum seekers' significantly poorer knowledge concerning HIV treatment might reflect the availability of HIV antiviral therapy in their countries of origin. Acknowledging that antiretroviral therapy minimizes the morbidity and mortality of HIV patients could motivate people to undergo HIV testing.

The proportions of those who knew somebody who was HIV positive was similar in both populations, which likely reflects the relatively low HIV prevalence in the asylum seekers' countries of origin, as well as that in Finland [3, 15].

The differences between the participants' socio-demographic determinants in the two studies are likely to explain some of the differences in the observed HIV KAP. The participants of the TIE study were more often men and less 
Table 3 Factors influencing the exposure to previous HIV testing

\begin{tabular}{|c|c|c|c|c|c|c|}
\hline \multirow[t]{3}{*}{ Variable } & \multicolumn{2}{|c|}{ TIE study 2014} & \multicolumn{4}{|c|}{ World aids day study $2014^{\mathrm{b}}$} \\
\hline & \multicolumn{2}{|c|}{ Previously tested for HIV } & \multicolumn{4}{|l|}{ Previously tested for HIV } \\
\hline & $\%(\mathrm{n})$ & Univariate $\mathrm{p}^{\mathrm{a}}$ & Weighted \% (95\% CI) & Univariate $\mathrm{p}$ & Multivariate $\mathrm{p}$ & $\mathrm{aOR}(95 \% \mathrm{CI})$ \\
\hline \multicolumn{7}{|l|}{ Gender } \\
\hline Men & $22.2(8)$ & 0.610 & $8.5(5.3-13.4)$ & $<\mathbf{0 . 0 0 0}$ & $<\mathbf{0 . 0 0 0}$ & $0.307(0.170-0.556)$ \\
\hline Women & $30.0(3)$ & & $27.9(22.9-33.4)$ & & & 1 \\
\hline Missing & 1 & & & & & \\
\hline \multicolumn{7}{|l|}{ Education } \\
\hline Primary or less & $21.4(6)$ & 0.546 & $23.0(14.1-35.1)$ & 0.279 & - & - \\
\hline Secondary or more & $29.4(5)$ & & $17.3(14.0-21.1)$ & & & \\
\hline Missing & 2 & & & & & \\
\hline \multicolumn{7}{|l|}{ Marital status } \\
\hline Single & $27.3(9)$ & 0.395 & $14.4(10.4-19.6)$ & 0.041 & 0.403 & $0.755(0.389-1.462)$ \\
\hline In a relationship & $15.4(2)$ & & $21.7(16.9-27.3)$ & & & 1 \\
\hline Missing & 1 & & & & & \\
\hline \multicolumn{7}{|l|}{ Time of arrival to Finland } \\
\hline In 2014 & $21.4(6)$ & 0.698 & NA & NA & NA & NA \\
\hline Before 2014 & $26.3(5)$ & & & & & \\
\hline Missing & 0 & & & & & \\
\hline \multicolumn{7}{|c|}{ UNGASS composite score (indicators 2-5) } \\
\hline All correct & $66.7(2)$ & 0.091 & $19.7(15.1-25.3)$ & 0.338 & - & - \\
\hline Some or none correct & $22.5(9)$ & & $16.4(12.3-21.4)$ & & & \\
\hline Missing & 4 & & & & & \\
\hline \multicolumn{7}{|c|}{ UNGASS 2: can a person reduce the risk of getting HIV by using a condom every time they have sex? } \\
\hline Yes & $26.1(6)$ & 0.301 & $19.1(15.7-23.1)$ & 0.053 & 0.248 & $1.786(0.667-4.784)$ \\
\hline No or unknown & $12.5(2)$ & & $9.5(4.6-18.7)$ & & & 1 \\
\hline Missing & 8 & & & & & \\
\hline \multicolumn{7}{|c|}{ UNGASS 3: Can a healthy-looking person have HIV? } \\
\hline Yes & $38.5(5)$ & 0.226 & $18.2(15.0-21.9)$ & $<\mathbf{0 . 0 0 0}$ & $<\mathbf{0 . 0 0 0}$ & c \\
\hline No or unkown & $20.7(6)$ & & c & & & \\
\hline Missing & 5 & & & & & \\
\hline \multicolumn{7}{|c|}{ UNGASS 4: can a person get HIV from mosquito bites? } \\
\hline No & $36.4(4)$ & 0.404 & $17.8(13.7-22.9)$ & 0.905 & - & - \\
\hline Yes or unknown & $23.3(7)$ & & $18.3(13.7-24.0)$ & & & \\
\hline Missing & 6 & & & & & \\
\hline \multicolumn{7}{|c|}{ UNGASS 5: Can a person get HIV by sharing food with someone who is infected? } \\
\hline No & $25.0(4)$ & 0.891 & $19.2(15.7-23.2)$ & 0.096 & 0.886 & $1.084(0.356-3.302)$ \\
\hline Yes or unknown & $26.9(7)$ & & $9.8(4.2-20.9)$ & & & 1 \\
\hline Missing & 5 & & & & & \\
\hline \multicolumn{7}{|l|}{ Can HIV be treated? } \\
\hline Yes & $36.4(4)$ & 0.404 & $19.5(15.8-23.8)$ & 0.090 & 0.115 & $1.734(0.875-3.438)$ \\
\hline No or unknown & $23.3(7)$ & & $12.5(7.6-19.9)$ & & & 1 \\
\hline Missing & 6 & & & & & \\
\hline \multicolumn{7}{|c|}{ Can a person get HIV through kissing? } \\
\hline No & $27.8(5)$ & 0.601 & $20.9(16.9-25.5)$ & 0.012 & 0.068 & $1.794(0.957-3.364)$ \\
\hline Yes or I don't know & $20.8(5)$ & & $11.3(7.1-17.3)$ & & & 1 \\
\hline Missing & 5 & & & & & \\
\hline \multicolumn{7}{|c|}{ Attitudes towards people living with HIV } \\
\hline Supportive & $50.0(8)$ & 0.068 & $17.7(13.7-22.5)$ & 0.926 & - & - \\
\hline Reserved & 0 & & $18.0(12.5-25.3)$ & & & \\
\hline
\end{tabular}


Table 3 (continued)

\begin{tabular}{|c|c|c|c|c|c|c|}
\hline \multirow[t]{3}{*}{ Variable } & \multirow{2}{*}{\multicolumn{2}{|c|}{$\frac{\text { TIE study } 2014}{\text { Previously tested for HIV }}$}} & \multicolumn{4}{|c|}{ World aids day study $2014^{\mathrm{b}}$} \\
\hline & & & \multicolumn{4}{|c|}{ Previously tested for HIV } \\
\hline & $\%(\mathrm{n})$ & Univariate $\mathrm{p}^{\mathrm{a}}$ & Weighted \% (95\% CI) & Univariate $\mathrm{p}$ & Multivariate $\mathrm{p}$ & $\mathrm{aOR}(95 \% \mathrm{CI})$ \\
\hline \multicolumn{7}{|c|}{ Unprotected sex within the last 6 months } \\
\hline Yes & NA & NA & $27.5(21.9-33.9)$ & $<0.000$ & 0.326 & $1.393(0.719-2.701)$ \\
\hline No & & & $11.0(7.7-15.5)$ & & & 1 \\
\hline \multicolumn{7}{|c|}{ Have you had unprotected sex with two or more partners during the last year? } \\
\hline Yes & NA & NA & $55.0(41.4-67.9)$ & $<\mathbf{0 . 0 0 0}$ & $<\mathbf{0 . 0 0 0}$ & $7.095(3.361-14.979)$ \\
\hline No & & & $13.5(10.6-17.0)$ & & & 1 \\
\hline
\end{tabular}

Significant findings bolded

$N A$ not applicable

${ }^{a}$ Pearson Chi squared

${ }^{b}$ All estimable interactions were unsignificant

${ }^{c}$ Due to quasi-complete separation in the data, the maximum likelihood estimate does not exist

educated than the participants of the WAD 2014 study. Previous studies have found better HIV knowledge to be associated with female gender [13, 23, 27, 28] and higher education [13, 23, 24, 27], although in this study, the findings were not so straightforward.

Exposure to previous HIV testing was surprisingly similar in both study populations despite the fact that, according to national guidelines, the majority of asylum seekers should be offered an HIV test within 3 months of registering their asylum application. Hence, the reported previous HIV testing among asylum seekers is most likely an underestimate. Poor knowledge regarding whether one has been previously tested suggests that health service providers have missed opportunities for health education. The general young adult population women's higher HIV testing rate than that of the men might be influenced by the universal antenatal HIV testing strategy in Finland [29].

Methods of delivering health education should be culturally relevant [30]. In this study, the young asylum seekers preferred passive methods of information sharing, such as television and the internet, as opposed to the general young adult population who preferred interpersonal strategies (school nurse, parents). In both populations, health care workers were named one of the top sources of sexual health education - a result also reaffirmed by previous studies [13]. Therefore, health professionals should actively discuss issues related to safe sex and HIV testing when encountering young people.

\section{Limitations}

The TIE study of young asylum seekers and the WAD 2014 study of the general young adult population were performed independently of each other, which might affect the comparability of the results. Both studies included the sameaged population and were performed during the same year. We aimed to control the differences in socio-demographic background by stratification but the low number of especially asylum seeking women in each stratum resulted in broad CIs. The authors evaluated the differences between the connotations in the study questions in the different surveys and deemed them to have minimal influence on the comparability of the results. The participation of the general young adult population in the WAD 2014 study was relatively poor (17.0\%), which limits the external validity of the results, despite weighting adjustment. The convenience sample of young asylum seekers in the TIE study is likely to include a sampling bias and the number of refusals was not assessed.

KAP surveys are feasible, widely used tools for assessing health behavior and for recognizing priority areas of health education. KAP assessments are based on the assumption that health literacy is a prerequisite for positive attitudes and healthy practices [14] and extensive literature supports this rationale [25, 28, 30, 31]. However, the external validity of KAP assessments has been criticized, as explaining health behavior is, in reality, far more complex [30]. Social desirability is likely to lead to respondents over-reporting healthpromoting practices such as previous HIV testing and safe sex. KAP surveys should be considered interventions, and researchers should pay attention to correcting misconceptions and providing participants with educational materials.

\section{Conclusions}

Young people in Finland, regardless of their residency status, have serious gaps in HIV knowledge. These gaps should be addressed in order to promote safe sex and HIV testing. 
In this study, certain knowledge gaps were more pronounced among the young asylum seekers than among the general population. Health education concerning HIV KAP might lower barriers to HIV testing. The period during which an asylum claim is being processed presents a window of opportunity for health education and HIV testing.

Acknowledgements Funding was provided by Suomen Tuberkuloosin Vastustamisyhdistyksen Säätiö, Helsingin Yliopisto, European Refugee Fund (ERF) and Ministry of Social Services and Health (FI).

\section{References}

1. World Health Organisation Regional Office for Europe. European action plan for HIV/AIDS 2012-2015. Stockholm: ECDC; 2011.

2. European Centre for Disease Prevention and Control [ECDC]. Migrant health: epidemiology of HIV and AIDS in migrant communities and ethnic minorities in EU/EEA countries. Stockholm: ECDC; 2010.

3. Hernando V, Alvarez-del Arco D, Alejos B, Monge S, AmatoGauci A,J, Noori T, Pharris A, del Amo J. HIV infection in migrant populations in the European Union and European economic area in 2007-2012: an epidemic on the move. J Acquir Immune Defic Syndr. 2015;70:204.

4. Jaakola S, Lyytikäinen O, Huusko S, Salmenlinna S, SavolainenKopra C, Liitsola K, Jalava J, Toropainen M, Nohynek H, Virtanen M, Löflund J, Kuusi M, Salminen M. Infectious diseases in Finland in 2016 [Tartuntataudit Suomessa 2016]. Helsinki: National Institute for Health and Welfare (THL); 2017.

5. UNAIDS. Migrants. The gap report 2014; 2014.

6. European Centre for Disease Prevention and Control [ECDC]. Migrant health: sexual transmission of HIV within migrant groups in the EU/EEA and implications for effective interventions. Stockholm: ECDC; 2013.

7. Deblonde J, De Koker P, Hamers F,F, Fontaine J, Luchters S, Temmerman M. Barriers to HIV testing in Europe: a systematic review. Eur J Public Health. 2010;20:422-432.

8. World Health Organization Regional Office for Europe. Strategy and action plan for refugee and migrant health in the WHO European Region. Stockholm: ECDC; 2015.

9. European Migration Network (EMN). Annual report on migration and asylum policy. Finland 2015. 2016.

10. Jablonka A, Solbach P, Nothdorft S, Hampel A, Schmidt RE, Behrens GMN. Low seroprevalence of syphilis and HIV in refugees and asylum seekers in Germany in 2015. Dtsch Med Wochenschr. 2016;141:e128.

11. Coppola N, Alessio L, Gualdieri L, Pisaturo M, Sagnelli C, Caprio N, Maffei R, Starace M, Angelillo IF, Pasquale G, Sagnelli E. Hepatitis $B$ virus, hepatitis $C$ virus and human immunodeficiency virus infection in undocumented migrants and refugees in southern Italy, January 2012 to June 2013. Eurosurveillance 2015;20:35.

12. Goosen S, Hoebe CJ, Waldhober Q, Kunst AE. High HIV prevalence among asylum seekers who gave birth in the Netherlands: a nationwide study based on antenatal HIV tests. PLoS ONE. 2015; 10:e0134724.

13. Uccella I, Petrelli A, Vescio M, De Carolis SF, Fazioli C, Pezzotti P, Rezza G. HIV rapid testing in the framework of an STI prevention project on a cohort of vulnerable Italians and immigrants. AIDS Care. 2017;29:996-1002.

14. United Nations General Assembly Special Session on HIV/AIDS (UNGASS). Monitoring the declaration of commitment on HIV/ AIDS-guidelines on construction of core indicators. Geneva: UNAIDS; 2002.
15. European Centre for Disease Prevention and Control [ECDC]. WHO Regional Office for Europe: HIV/AIDS surveillance in Europe 2015. Stockholm: ECDC; 2016.

16. Karki T, Napoli C, Riccardo F, Fabiani M, Dente MG, Carballo M, Noori T, Declich S. Screening for infectious diseases among newly arrived migrants in EU/EEA countries-varying practices but consensus on the utility of screening. Int J Environ Res Public Health. 2014;11:11004-14.

17. Statistics Finland: Statistics Finland's PX-Web databases. 2017.

18. United Nations General Assembly Special Session (UNGASS) on HIV/AIDS. guidelines on construction of core indicators; Monitoring the Declaration of Commitment on HIV/AIDS. Geneva: UNAIDS; 2009.

19. Ríos E, Ferrer L, Casabona J, Caylá J, Avecilla A, Gómez I, Prat J, Edison J, Pérez O, García S, Torán P, Ruiz M, Gros T, Rodríguez L, Arribas D, Folch C, Esteve A. Knowledge of HIV and sexuallytransmitted diseases in Latin American and Maghrebi immigrants in Catalonia (Spain). Gac Sanit. 2009;23:533-8.

20. Koch-Göppert G, Gräser S, Krischke N. Barrieren und Ressourcen der Inanspruchnahme von HIV-Präventionsangeboten für Afrikanische Migrantinnen. Gesundheitswesen 2015;77:33-4.

21. Kouta C, Phellas C, Charis K. Knowledge, attitudes and perceptions of immigrants from third countries in Cyprus, on HIV/AIDS and sexual and reproductive health. The implication of nursing ethics to healthcare. Health Sci J. 2013;7:258-68.

22. Dias S, Marques A, Gama A, Martins MO. HIV risky sexual behaviors and HIV infection among immigrants: a cross-sectional study in Lisbon, Portugal. Int J Environ Res Public Health. 2014;11:8552-66.

23. Lazarus JV, Himedan MH, Rosendal Ostergaard L, Liljestrand J. HIV/AIDS knowledge and condom use among Somali and Sudanese immigrants in Denmark. Scand J Public Health. 2006;34:92-9.

24. Kuznetsov L, Matterne U, Crispin A, Ruzicka T, Zippel SA, Kuznetsov AV. Knowledge, attitude and behavioral intention to act regarding HIV infection and prevention in immigrants from the former Soviet Union in Germany: a comparative study with the native population. J Immigr Minor Health. 2013;15:68-77.

25. Santos-Hovener C, Zimmermann R, Kucherer C, Batzing-Feigenbaum J, Wildner S, Hamouda O, Marcus U. Conversation about Serostatus decreases risk of acquiring HIV: results from a case control study comparing MSM with recent HIV infection and HIV negative controls. BMC Public Health. 2014;14:453.

26. Brannstrom J, Sonnerborg A, Svedhem V, Neogi U, Marrone G. A high rate of HIV-1 acquisition post immigration among migrants in Sweden determined by a CD4 T-cell decline trajectory model. HIV Med. 2017. https://doi.org/10.1111/hiv.12509

27. Santos-Hovener C, Marcus U, Koschollek C, Oudini H, Wiebe M, Ouedraogo OI, Thorlie A, Bremer V, Hamouda O, Dierks ML, An der Heiden M, Krause G. Determinants of HIV, viral hepatitis and STI prevention needs among African migrants in Germany; a crosssectional survey on knowledge, attitudes, behaviors and practices. BMC Public Health. 2015;15:753.

28. Akinsulure-Smith AM. Exploring HIV knowledge, risk and protective factors among west African forced migrants in New York City. J Immigr Minor Health. 2014;16:481-91.

29. European Centre for Disease Prevention and Control [ECDC]. Technical Report. Antenatal screening for HIV, hepatitis B, syphilis and rubella susceptibility in the EU/EEA. Stockholm: ECDC; 2016.

30. MacNeil JM, Hogle J. Applying social, behavioral and evaluation research to developing country HIV prevention programs. AIDS 1998;12(Suppl 2):S99-108.

31. Johnson WD, Hedges LV, Diaz RM. Interventions to modify sexual risk behaviors for preventing HIV infection in men who have sex with men. Cochrane Database Syst Rev. 2003;1:CD001230. 